\title{
The use of a data logger for monitoring rat activity
}

\author{
ARTHUR E. HAWKINS \\ Unilever Research Laboratory, Colworth House, \\ Sharnbrook, Bedford, England
}

\begin{abstract}
KURZFASSUNG: Die Verwendung eines Datenerfassungssystems zur Registrierung der Aktivität von Ratten. Ein Gerät wird beschrieben, das die Aktivitätsregistrierung von Ratten in Einzelkäfigen über mehrere Tage hinweg ermöglicht. Durch eine elektronische Schaltung, welche mit dem Käfigboden verbunden ist, wird ein Spannungsunterschied erzeugt. Als Maß für die Aktivität der Tiere während eines bestimmten Zeitabschnittes dient die Größe des Spannungsunterschiedes. Die Aktivität mehrerer in verschiedenen Einzelkäfigen gehaltenen Ratten kann mittels Rechenmaschinen auf Lochpapierstreifen registriert werden. Hierbei werden die erzeugten Spannungsunterschiede fortlaufend durch ein geeignetes Datenerfassungssystem abgetastet.
\end{abstract}

\section{INTRODUCTION}

The effects of processing on the nutritional value of foodstuffs and the possible harmful effects of additives are most conveniently studied by feeding diets containing the materials to experimental animals. Rats are commonly used for this purpose, and a measure of their condition is obtained by weighing at regular intervals. The method is not very sensitive, however; the system to be described here attempts to detect far smaller changes in the condition of rats.

A child can be seen to be "out of sorts" by his parents by the change in pattern and level of his activity. It was believed that recording the activity of rats in individual cages would be viable providing it was possible to handle many rats simultaneously to cover biological variability. It must be emphasized that the processing of the activity data is, in this context, as vital as its acquisition. If the data cannot be processed by a computer it has no value whatsoever, for no-one is prepared to sit down and analyse thousands of feet of recorder chart. A variety of devices is available for studying the activity of laboratory animals, but none could be found which satisfied this criterion.

\section{DESCRIPTION OF APPARATUS}

The normal mesh floor of each rat cage was replaced by a floor consisting of parallel conductors as shown in Figure 1, where alternate conductors are connected electrically in parallel. As the rat moves about on such a floor there are changes in the resi- 
stance between the two sets of conductors due to the varying pressure and area of contact. The value of the resistance varies between several megohms and a few kilohms when the feet are wet with urine.

A low voltage source and a resistance, $R$, of the order of megohms, in series with the floor permit the resistance changes to be detected as potential difference changes

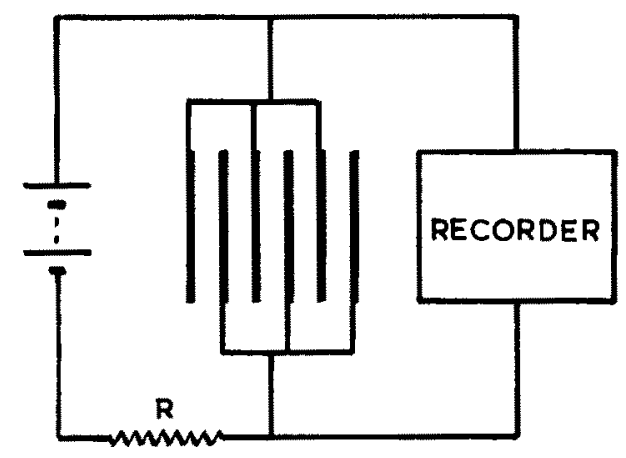

Fig. 1: Floor circuit with potentiometric recording

across the floor or across $\mathrm{R}$ without any possibility of producing physiological effects in the rat. A potentiometric recorder can then be used to provide a continuous record of the activity of the rat with respect to time.

At this stage in the work a difficulty arose. The rat has an inquisitive nature, very sharp teeth and strong neck muscles. The rats lifted the floors and chewed through the wiring. Of several types of "rat proof" floor developed, the simplest has sides of $3 / 4$ " O. D. perspex tube cut down its length with $1 / 8^{\prime \prime}$ brass or stainless steel rods cemented into place through holes in the sides at $1 / 2{ }^{\prime \prime}$ intervals. The rods are interconnected and half-tube sides filled with an epoxy resin.

Very satisfactory potentiometric recorder traces of the activity of rats were obtained using these floors. As much detail of the varying D. C. signal as was required

Table 1

Characteristic frequencies of resistance change

\begin{tabular}{|lcl|}
\hline Type of activity & \multicolumn{1}{c}{$\begin{array}{c}\text { Number of changes per minute } \\
\text { (Measured over 15 second chart intervals) }\end{array}$} & \multicolumn{1}{c|}{ Comments } \\
\hline Rest & $0-12$ & $75 \%$ less than 5 \\
Slow locomotor & $4-30$ & $75 \%$ above 10 \\
Fast locomotor & $30-400$ & $\begin{array}{l}\text { Ultra-violet } \\
\text { galvanometer recorder } \\
\text { used for very fast } \\
\text { locomotion } \\
\end{array}$ \\
& c 60 & $\begin{array}{l}\text { Some movement missed } \\
\text { when rat on hind legs }\end{array}$ \\
Grooming & & \\
& &
\end{tabular}


could be obtained by increasing the recorder paper speed and such recordings have shown that the various types of activity have reasonably consistent characteristic frequencies of resistance change. The values obtained are given in Table 1.

It appeared from these results that it should be possible to attach an electronic circuit to each floor which would produce a series of equal pulses at these characteristic

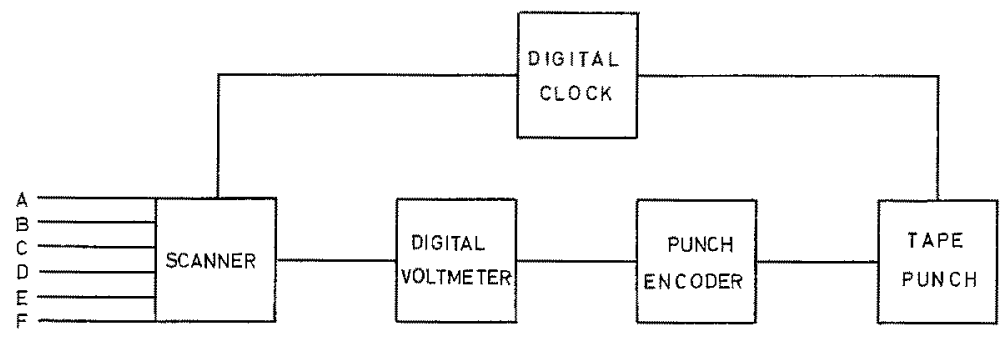

Fig. 2: Block diagram of a data logger

frequencies. It should then be possible to sum these pulses over some fixed period of time to give an integrated value representing the activity over that period of time. If this were possible, then entry into a computer would be simple since the principles of data logging would be applicable.

To make this clear, it is necessary to outline the operation of a data logger. The arrangement of the basic units is shown in Figure 2. A scanner, either free running or clock controlled, examines in sequence a series of voltage inputs $A, B, C$. . etc., finally returning to $A$ to proceed all over again. The scanner couples to each channel for a few milliseconds, and the voltage present is fed to an analogue-to-digital converter, such as a digital voltmeter. The digital voltmeter commands a drive unit to operate a printer, electric typewriter or paper tape punch to record the voltage with which it has been presented. The time of collection of the voltage may also be included with the data recorded.

The number of channels examined per second may be large or small depending upon the complexity and cost of the logger. In this work a relatively low speed, inexpensive data logger (the "Compact Logger" type LY 1470 by The Solartron Electronic Group Ltd., Farnborough, England) has been used. This will scan each channel every $1 / 3,1 / 2,1$ or 2 seconds depending on the display form and number of digits required. In its basic form this logger will handle 20 inputs, but extra modules increase this to 50 or 100 inputs.

If an integrating system were available, the time interval between successive looks at each cage might be approximately 7 seconds with 20 cages. The values, punched out in code on paper tape for later computer processing, would thus represent the average activity for 7 seconds. This is virtually continuous recording of activity in a form suitable for computer analysis of time and level differences between rats. With a free running scanner it would not be necessary to record time since the starting time of the run and the fixed interval between readings could be included in the computer programme. 
The requisite integrating system has been developed, and its principle is illustrated in Figure 3. The varying D. C. signal is taken from the floor rather than from the fixed resistance for convenience. The signal is differentiated and amplified and either the negative or positive going spike removed to give unidirectional current spikes of varying magnitudes, all of which operate the relay.

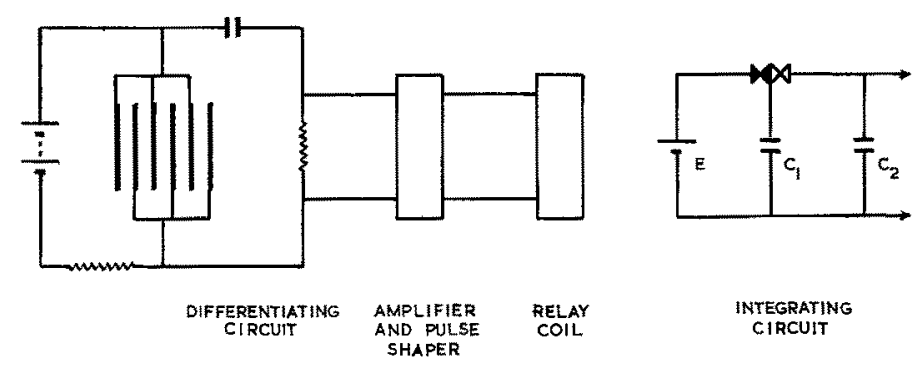

Fig. 3: Floor circuit with an integrating system

The relay has a changeover contact and, at each pulse, a small charged capacitor $\mathrm{C}_{1}$ is connected to a large, high leakage resistance, solid tantalum capacitor $\mathrm{C}_{2}$. Thus at each pulse an equal increment of charge $\mathrm{EC}_{1}$ is shared with $\mathrm{C}_{2}$. When $\mathrm{C}_{1}$ goes back for recharging the potential difference across $\mathrm{C}_{2}$ is $\mathrm{EC}_{1} /\left(\mathrm{C}_{1}+\mathrm{C}_{2}\right)$. On the next transfer of charge the potential difference is not quite $2 \mathrm{EC}_{1} /\left(\mathrm{C}_{1}+\mathrm{C}_{2}\right)$ nor on the third quite $3 \mathrm{EC}_{1} /\left(\mathrm{C}_{1}+\mathrm{C}_{2}\right)$ because $\mathrm{C}_{1}$ takes back some charge each time and the amount taken back increases with each successive operation. The full expression for the potential difference $V_{n}$ across $C_{2}$ after $n$ pulses is given by

$$
V_{n}=\frac{E C_{1}}{\left(C_{1}+C_{2}\right)}\left\{1+\frac{C_{2}}{\left(C_{1}+C_{2}\right)}+\left(\frac{C_{2}}{C_{1}+C_{2}}\right)^{2}+\ldots\left(\frac{C_{2}}{C_{1}+C_{2}}\right)^{n-1}\right\},
$$

but $\mathrm{C}_{1} \ll \mathrm{C}_{2}$ and only a few pulses are involved in the time intervals concerned, so, in practice, the potential difference across $C_{2}$ may be taken as directly proportional to the number of pulses received and, in turn, related to the activity during the time interval.

The "Compact Logger" has one essential feature for operation with this type of circuit. When the scanner switches from input $A$ to input $B$, a 12 volt pulse appears at terminals below the $\mathrm{A}$ input terminals and is available to operate a relay to discharge the capacitor $\mathrm{C}_{2}$. Similarly on leaving $\mathrm{B}, \mathrm{C} \ldots$ the relevant capacitors can be discharged. Thus, when the scanner switches to each unit, it receives only the voltage developed during the previous 7 seconds or whatever cycling period is being used.

The principles outlined above are incorporated in the circuit shown in Figure 4. The varying $D$. C. signal is differentiated by $C_{1} R_{4}$, amplified by the germanium transistor $\mathrm{VT}_{1}$ (Mullard Ltd., London, England) and again differentiated by $\mathrm{C}_{3} \mathrm{R}_{8}$ to shorten the pulse length. Further amplification is provided by $\mathrm{VT}_{2}$ and $\mathrm{VT}_{3}$. The use of a silicon transistor for $\mathrm{VT}_{3}$ is essential for two reasons: (I) the sensitivity control $R_{11}$, which is used to match the individual circuits, must not act as a biassing control for $\mathrm{VT}_{4}$, which would happen with the high leakage current of a germanium transistor, and 
(II) the high leakage current with a germanium transistor would make the circuit very temperature sensitive. The changeover relay (721 series by Magnetic Devices Ltd., Newmarket, England) is driven by $\mathrm{VT}_{4}$, and the integration performed by $\mathrm{C}_{7}$ and $\mathrm{C}_{8}$.

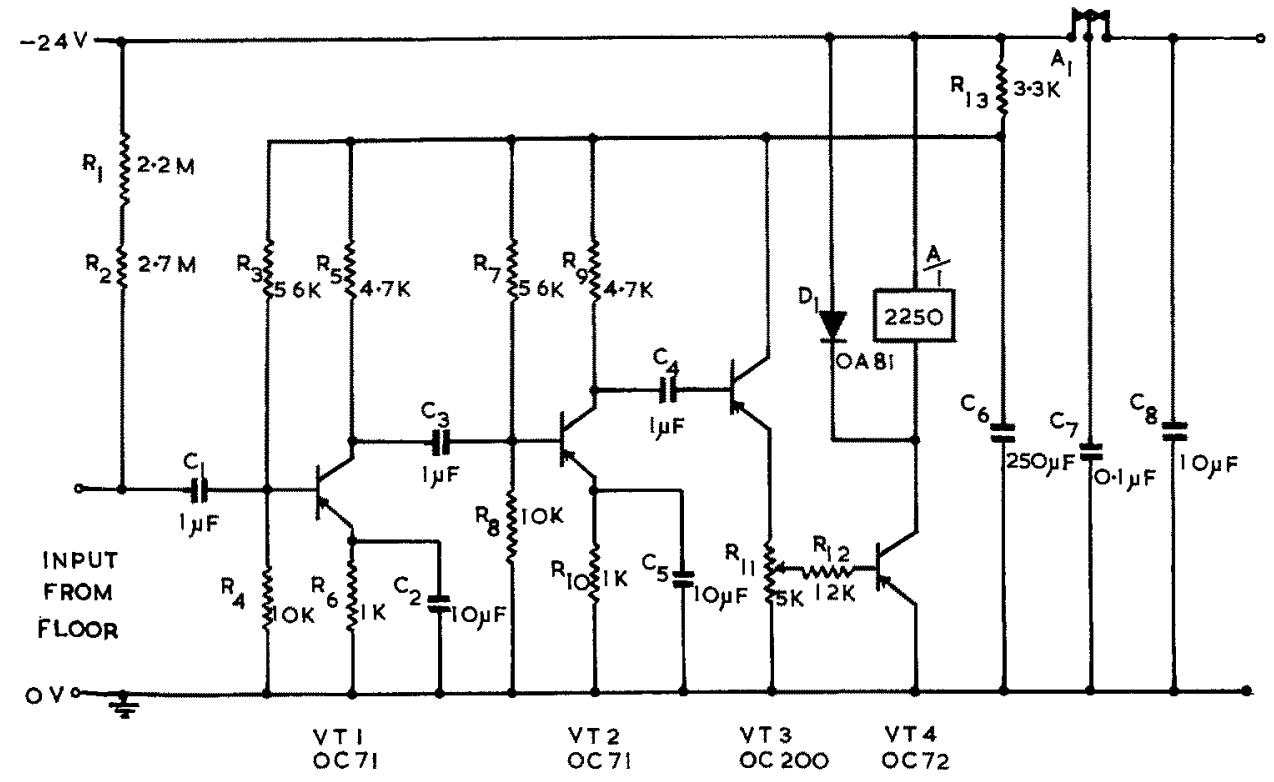

Fig. 4 : Circuit diagram of the integrator

The units are built on plug-in circuit boards which are rack mounted in a small volume and easily replaced if they should fail.

\section{EXPERIMENTAL RESULTS AND CONCLUSION}

So far the complete system has only been used with print-out from the Compact Logger and no computer analysis has been attempted. The apparatus gave excellent results, responding immediately to changes of activity and providing a quantitative measure of the activity.

A 100 channel system is being installed in two rooms, the animal room being soundproofed from the instrument room with permanent wiring between the two. With this apparatus it will be possible to determine whether the fineness of detail required for the purposes outlined in the introduction can be achieved. It seems certain, however, that the use of data logging is sound for this and similar purposes.

\section{SUMMARY}

1. A floor has been constructed which, in a standard cage with simple associated circuitry, permits the potentiometric recording of the activity of individual rats by means of changes of floor resistance. 
2. The main activities of rats have been found to produce characteristic frequencies of floor resistance change.

3. A transistor circuit has been devised which, using these characteristic frequencies, produces a voltage output proportional to the activity which has occurred during a short time interval.

4. It has been shown that a Data Logger may be used to monitor these voltage outputs and produce an activity record of the rats in many cages suitable for computer analysis.

\section{ACKNOWLEDGEMENT}

The principles outlined in this short communication have been turned into practicable apparatus by Mr. J. E. Couper to whom a great deal of the success of this project should be attributed. 